\title{
Deep brain stimulation for Parkinson's disease: where do we stand?
}

\author{
Alberto Albanese ${ }^{1,2 *}$ and Luigi Romito ${ }^{1,2}$ \\ Neurologia I, Fondazione IRCCS Istituto Neurologico Carlo Besta, Milano, Italy \\ 2 Istituto di Neurologia, Università Cattolica del Sacro Cuore, Milano, Italy \\ *Correspondence: alberto.albanese@unicatt.it
}

Deep brain stimulation (DBS) is an established treatment for Parkinson's disease (PD) patients who present with disabling motor complications, such as fluctuations and dyskinesias unmanageable by medical treatment alone (The Deep-Brain Stimulation for Parkinson's Disease Study Group, 2001). In recent years, two main targets have emerged: the subthalamic nucleus (STN) and the globus pallidum internum (GPi). These brain nuclei differ significantly for anatomical connections, size, and functional role within the basal ganglia. The available clinical experience, arising either from mono-center or multi-center studies, is more detailed for STN compared to GPi DBS. First, short-term data have shown that, compared to best medical treatment, STN stimulation is more efficacious for controlling dyskinesias, motor function, and quality of life, but is associated with a higher risk of serious adverse events (Deuschl et al., 2006). Furthermore, long-term sustained motor efficacy of STN implants has been demonstrated for up to 8 years now (Fasano et al., 2010), compared to 5.5 years of GPi (Moro et al., 2010b). Medication- and stimulation-resistant symptoms, mainly axial signs (such as gait and postural impairment) become evident after 5 years after STN implants. These features are likely due to disease progression, which also require either the increase of dopaminergic medication dosage or of the total electrical energy delivered to the STN (Fasano et al., 2010).

Three recent studies (two randomized and one uncontrolled) have compared the effects of STN and GPi stimulation in complicated PD patients (Table 1). Taken together, they indicate that STN and GPi stimulations have similarities and differences. They both improve motor signs of PD and reduce dyskinesias; however, STN stimulation generates more pronounced motor improvement allowing to reduce dopaminergic medication to a higher degree. The trade-off is a higher incidence of treatment-related adverse events, in particular speech disturbances and postoperative confusion, in patients receiving STN implants. These trials have intrinsic methodological limitations that curb their external validity, particularly due to the multi-center design with heterogeneity of targeting techniques, equipment, selection criteria, and post-operative procedures. Currently, most centers in Europe and in North America perform implants in the STN rather than in the GPi; in most instances, this preference is based on the team experience. Recent data indicate, however, that target selection could be tailored to the patient's clinical and personal profile: GPi DBS may suit better patients with dose-limiting dyskinesias or behavioral and cognitive issues, whereas STN DBS may be more indicated for younger patients with prominent akinesia and tremor or with behavioral disorders related to dopaminergic medication.

Table 1 | Published data comparing bilateral GPi and STN implants in PD.

\begin{tabular}{llll}
\hline & $\begin{array}{l}\text { GPi } \\
\text { stimulation }\end{array}$ & $\begin{array}{l}\text { STN } \\
\text { stimulation }\end{array}$ & Reference \\
\hline MOTOR STATUS & $-39 \% \S$ & $-48 \% \S$ & Anderson et al. (2005) \\
UPDRS motor change at 1 year & $-43.8 \% \S$ & $-53.9 \% \S$ & Moro et al. (2010b) \\
UPDRS motor change at 2-4 years & $-28.2 \% \S$ & $-25.3 \% \S$ & Follett et al. (2010) \\
UPDRS motor change at 5-6 years & $-37.1 \% \S$ & $-50.4 \% \S$ & Moro et al. (2010b) \\
FUNCTIONAL STATUS & & & \\
UPDRS activities of daily living at last FU & $0.0 \%$ & $0.0 \%$ & Anderson et al. (2005) \\
& $22.4 \% \S$ & $64.7 \% \S$ & Moro et al. (2010b) \\
TREATMENT STATUS & $-17.2 \%$ & $-11.5 \%$ & Follett et al. (2010) \\
\hline LEDD change at last FU & $-3 \%$ & $-38 \% \S$ & Anderson et al. (2005) \\
& $-22.6 \%$ & $-55.9 \% \S$ & Moro et al. (2010b)
\end{tabular}

UPDRS motor change was evaluated with stimulation turned on, but without antiparkinsonian medication; UPDRS activities of daily living was evaluated with stimulation turned on and with antiparkinsonian medications. §Pre-operative and post-operative comparison statistically significant; LEDD, levodopa-equivalent daily dose. Negative data indicate improvement or medication reduction, positive data indicate the opposite. 
committee (Defer et al., 1999) that recommend to select patients with at least 5 years of disease duration, with significant motor disability and no cognitive or psychiatric impairment. No recommendation is available on age or disease duration limits for STN or GPi implants. The few studies addressing the effects of age or disease duration at time of implant proved to be inconclusive. An uncontrolled study has identified age and pre-operative levodopa responsiveness and, to a lesser extent, disease duration, as predictors of outcome for bilateral STN DBS (Charles et al., 2002). This was not confirmed by a systematic review that found no evidence of better surgical outcome in younger patients who received STN DBS (Kleiner-Fisman et al., 2006). More recently, it has been agreed that the overall motor improvement is unrelated to age at time of implant (Derost et al., 2007), although quality of life improvements occur only in younger patients.

The question as to when is the optimal timing for DBS implants remains very concrete. An 18-month prospective trial significantly favored early DBS over early medical therapy alone in measures of quality of life, motor performance without medication, levodopa-induced motor complications, and medication reduction (Schupbach et al., 2007). The adverse events were mild or transient, and overall psychiatric morbidity and anxiety improved more in the surgical group. This study suggested that treating younger patients before symptoms become disabling should help many remain productive longer than without surgery, making surgery an ethically acceptable option for younger, less severely compromised patients. Two randomized controlled trials aimed at assessing the usefulness of early STN DBS are currently underway: the EARLYSTIM multi-center German-French study (ClinicalTrials.gov NCT00354133) and the North American mono-center study (ClinicalTrials.gov NCT00282152). The results of these trials are expected not before a couple of years.

A reason for performing STN implants earlier also stems by the aim to prevent the occurrence of a dopaminergic dysregulation syndrome. Data regarding the effect of STN DBS on dopamine dysregulation, impulse control disorders, and punding in PD are still limited and conflicting: available observations report that these features may develop after DBS, or otherwise improve, persist, or worsen (Bandini et al., 2007; Lim et al., 2009). The main issue to solve is what factors allow predicting behavioral variations after implants. A likely hypothesis is that medication or DBS may differentially affect some preexisting personality features; medication dosage and stimulation settings may represent key variables of outcome. There is also evidence that STN DBS causes executive inhibitory deficits and impulsive behavior under high-conflict conditions; these phenomena are probably due to an impulsive decision-making that may be explained by an inability to self-modulate decision times as a function of conflict (Frank et al., 2007). STN DBS may act directly on the gating mechanism involved in response initiation and proactive inhibitory commands (Ballanger et al., 2009).It is not known whether these phenomena are affected by patients' age or disease duration.

In recent years, other potential targets for PD have been investigated. Experimental findings suggest that low frequency DBS of the pedunculopontine nucleus (PPN) could improve some of the axial symptoms of the disease unresponsive to STN DBS and dopaminergic therapy, particularly freezing of gait and the frequency of falls (Moro et al., 2010a), but the results of a recent double-blind cross-over study (Ferraye et al., 2010) have frozen expectations. Simultaneous STN and PPN stimulation has also been performed with the aim to provide better motor control to patients (Stefani et al., 2007). New devices will allow controlling four or more electrodes, allowing to perform simultaneous multiple target stimulation with just one implantable pulse generator.

The most expected innovation, however, is technical. In order to optimize the efficacy of DBS and reduce unwanted current spread to adjacent brain structures, electrodes need to be redesigned and active contacts should have improved geometry. Nanotechnology will permit a progressive miniaturization of hardware components and ideally the improvement of lengthy connecting cables and distant pulse generators. The development of sensor-driven pacing has been a landmark innovation for cardiac pacemakers, enabling the device to respond to physiologic demands. Similarly, the development of responsive DBS stimulators, would allow moving beyond the current paradigms of treatment, toward a stimulation adjusted to motor context and movement needs, a physiological function that cannot be provided by medication.

\section{REFERENCES}

Anderson, V. C., Burchiel, K. J., Hogarth, P., Favre, J., and Hammerstad, J. P. (2005). Pallidal vs subthalamic nucleus deep brain stimulation in Parkinson disease. Arch. Neurol. 62, 554-560.

Ballanger, B., van Eimeren, T., Moro, E., Lozano, A. M., Hamani, C., Boulinguez, P., Pellecchia, G., Houle, S. Poon, Y. Y., Lang, A. E., and Strafella, A. P. (2009). Stimulation of the subthalamic nucleus and impulsivity: release your horses. Ann. Neurol. 66, 817-824.

Bandini, F., Primavera, A., Pizzorno, M., and Cocito, L. (2007). Using STN DBS and medication reduction as a strategy to treat pathological gambling in Parkinson's disease. Parkinsonism Relat. Disord. 13, 369-371.

Charles, P. D., Van Blercom, N., Krack, P., Lee, S. L., Xie, J., Besson, G., Benabid, A. L., and Pollak, P. (2002). Predictors of effective bilateral subthalamic nucleus stimulation for PD. Neurology 59, 932-934.

Defer, G. L., Widner, H., Marie, R. M., Remy, P., and Levivier, M. (1999). Core assessment program for surgical interventional therapies in Parkinson's disease (CAPSIT-PD). Mov. Disord. 14, 572-584.

Derost, P. P., Ouchchane, L., Morand, D., Ulla, M., Llorca, P. M., Barget, M., Debilly, B., Lemaire, J. J., and Durif, F. (2007). Is DBS-STN appropriate to treat severe Parkinson disease in an elderly population? Neurology 68, 1345-1355.

Deuschl, G., Schade-Brittinger, C., Krack, P., Volkmann, J., Schafer, H., Botzel, K., Daniels, C., Deutschländer, A., Dillmann, U., Eisner, W., Gruber, D., Hamel, W., Herzog, J., Hilker, R., Klebe, S., Kloss, M., Koy, J., Krause, M., Kupsch, A., Lorenz, D., Lorenzl, S., Mehdorn, H.M., Moringlane, J. R., Oertel, W., Pinsker, M. O., Reichmann, H., Reuss, A., Schneider, G. H., Schnitzler, A., Steude, U., Sturm, V., Timmermann, L., Tronnier, V., Trottenberg, T., Wojtecki, L., Wolf, E., Poewe, W., Voges, J., and German Parkinson Study Group, Neurostimulation Section. (2006). A randomized trial of deep-brain stimulation for Parkinson's disease. N. Engl. J. Med. 355, 896-908.

Fasano, A., Romito, L. M., Daniele, A., Piano, C., Zinno, M., Bentivoglio, A. R., and Albanese, A. (2010). Motor and cognitive outcome in patients with Parkinson's disease 8 years after subthalamic implants. Brain 133 , 2664-2676.

Ferraye, M. U., Debu, B., Fraix, V., Goetz, L., Ardouin, C., Yelnik, J., Henry-Lagrange, C., Seigneuret, E., Piallat, B., Krack, P., Le Bas, J. F., Benabid, A. L., Chabardès, S., and Pollak, P. (2010). Effects of pedunculopontine nucleus area stimulation on gait disorders in Parkinson's disease. Brain 133, 205-214.

Follett, K. A., Weaver, F. M., Stern, M., Hur, K., Harris, C. L., Luo, P., Marks, W. J. Jr., Rothlind, J., Sagher, O., Moy, C., Pahwa, R., Burchiel, K., Hogarth, P., Lai, E. C., Duda, J. E., Holloway, K., Samii, A., Horn, S., Bronstein, J. M., Stoner, G., Starr, P. A., Simpson, R., Baltuch, G., De Salles, A., Huang, G. D., Reda, D. J., and CSP 468 Study Group. (2010). Pallidal versus subthalamic deep-brain stimulation for Parkinson's disease. N. Engl. J. Med. 362, 2077-2091.

Frank, M. J., Samanta, J., Moustafa, A. A., and Sherman, S. J. (2007). Hold your horses: impulsivity, deep brain 
stimulation, and medication in parkinsonism. Science 318, 1309-1312.

Holmberg, B., Corneliusson, O., and Elam, M. (2005). Bilateral stimulation of nucleus subthalamicus in advanced Parkinson's disease: no effects on, and of, autonomic dysfunction. Mov. Disord. 20, 976-981.

Kleiner-Fisman, G., Herzog, J., Fisman, D. N., Tamma, F., Lyons, K. E., Pahwa, R., Lang, A. E., and Deuschl, G. (2006). Subthalamic nucleus deep brain stimulation: summary and meta-analysis of outcomes. Mov. Disord. 21(Suppl. 14), S290-S304.

Lim, S. Y., O'Sullivan, S. S., Kotschet, K., Gallagher, D. A., Lacey, C., Lawrence, A. D., Lees, A. J., O’Sullivan, D. J., Peppard, R. F., Rodrigues, J. P., Schrag, A., Silberstein, P., Tisch, S., and Evans, A. H. (2009). Dopamine dysregulation syndrome, impulse control disorders and punding after deep brain stimulation surgery for Parkinson's disease. J. Clin. Neurosci. 16, 1148-1152.

Moro, E., Hamani, C., Poon, Y. Y., Al-Khairallah, T., Dostrovsky, J. O., Hutchison, W. D., and Lozano, A. M. (2010a). Unilateral pedunculopontine stimulation improves falls in Parkinson's disease. Brain 133, 215-224.
Moro, E., Lozano, A. M., Pollak, P., Agid, Y., Rehncrona, S., Volkmann, J., Kulisevsky, J., Obeso, J. A., Albanese, A., Hariz, M. I., Quinn, N.P., Speelman, J. D., Benabid, A. L., Fraix, V., Mendes, A., Welter, M. L., Houeto, J. L., Cornu, P., Dormont, D., Tornqvist, A. L., Ekberg, R., Schnitzler, A., Timmermann, L., Wojtecki, L., Gironell, A., Rodriguez-Oroz, M. C., Guridi, J., Bentivoglio, A. R., Contarino, M. F., Romito, L., Scerrati, M., Janssens, M., and Lang, A. E. (2010b). Long-term results of a multicenter study on subthalamic and pallidal stimulation in Parkinson's disease. Mov. Disord. 25, 578-586.

Schupbach, W. M., Maltete, D., Houeto, J. L., du Montcel, S. T., Mallet, L., Welter, M. L., Gargiulo, M., Béhar, C., Bonnet, A. M., Czernecki, V., Pidoux, B., Navarro, S., Dormont, D., Cornu, P., and Agid, Y. (2007). Neurosurgery at an earlier stage of Parkinson disease: a randomized, controlled trial. Neurology 68, 267-271.

Stefani, A., Lozano, A. M., Peppe, A., Stanzione, P., Galati, S., Tropepi, D., Pierantozzi, M., Brusa, L., Scarnati, E., and Mazzone, P. (2007). Bilateral deep brain stimulation of the pedunculopontine and subthalamic nuclei in severe Parkinson's disease. Brain 130, 1596-1607.
The Deep-Brain Stimulation for Parkinson's Disease Study Group. (2001). Deep-brain stimulation of the subthalamic nucleus or the pars interna of the globus pallidus in Parkinson's disease. N. Engl. J. Med. 345, 956-963.

Zibetti, M., Rizzi, L., Colloca, L., Cinquepalmi, A., Angrisano, S., Castelli, L., Lanotte, M., and Lopiano, L. (2010). Probable REM sleep behaviour disorder and STN-DBS outcome in Parkinson's Disease. Parkinsonism Relat. Disord. 16, 265-269.

Received: 14March 2011; accepted: 10 May 2011; published online: 24 May 2011.

Citation: Albanese A and Romito L (2011) Deep brain stimulation for Parkinson's disease: where do we stand? Front. Neur. 2:33. doi: 10.3389/fneur.2011.00033

This article was submitted to Frontiers in Movement Disorders, a specialty of Frontiers in Neurology.

Copyright (c) 2011 Albanese and Romito. This is an openaccess article subject to a non-exclusive license between the authors and Frontiers Media SA, which permits use, distribution and reproduction in other forums, provided the original authors and source are credited and other Frontiers conditions are complied with. 